\title{
Gene Expression Changes Associated with the Loss of Heterogeneous Nuclear Ribonucleoprotein M Function
}

\section{Jun-ichi Takino', Kentaro Nagamine ${ }^{1}$, Mikoto Suzuki' ${ }^{1}$, Akiko Sakasai-Sakai², Masayoshi Takeuchi², Takamitsu Hori ${ }^{1}$}

${ }^{1}$ Department of Biochemistry, Hiroshima International University, Hiroshima, Japan

${ }^{2}$ Department of Advanced Medicine, Kanazawa Medical University, Ishikawa, Japan

Email: k-nagami@ps.hirokoku-u.ac.jp

How to cite this paper: Takino, J., Nagamine, K., Suzuki, M., Sakasai-Sakai, A., Takeuchi, M. and Hori, T. (2017) Gene Expression Changes Associated with the Loss of Heterogeneous Nuclear Ribonucleoprotein M Function. American Journal of Molecular Biology, 7, 87-98.

https://doi.org/10.4236/ajmb.2017.72007

Received: January 25, 2017

Accepted: April 25, 2017

Published: April 28, 2017

Copyright $\odot 2017$ by authors and Scientific Research Publishing Inc. This work is licensed under the Creative Commons Attribution International License (CC BY 4.0).

http://creativecommons.org/licenses/by/4.0/

\begin{abstract}
Advanced glycation endproducts (AGEs) are formed by the nonenzymatic reaction of sugars with proteins. Glycation may adversely affect proteins, such as by inducing a loss of function. It has been shown that glyceraldehyde-derived AGEs (Glycer-AGEs) accumulate in the liver of patients with nonalcoholic steatohepatitis (NASH). Previously, we showed the formation of intracellular Glycer-AGEs upon exposure of hepatocytes to fructose in vitro, and identified an RNA-binding protein, heterogeneous nuclear ribonucleoprotein M (HNRNPM), as a target for glycation. However, the impact of glycated HNRNPM in NASH remains poorly understood. In this study, we examined gene expression changes caused by HNRNPM knockdown, and investigated the up- and down-regulated genes as noninvasive biomarker candidates for NASH. Microarray analysis after HNRNPM knockdown showed that the levels of 138 transcripts were increased, while those of 100 transcripts were decreased as compared with those in the control. Gene Ontology-based functional analysis showed that 14 upregulated and 9 downregulated genes were associated with the extracellular space, which may enable their detection using blood tests. Among these, six of the up- and down-regulated genes were associated with the extracellular exosome. These results suggest that the loss of HNRNPM function by glycation is reflected extracellularly. Therefore, the identified genes may serve as noninvasive biomarkers for Glycer-AGEsrelated NASH.
\end{abstract}

\section{Keywords}

Glycation, Nonalcoholic Steatohepatitis, Heterogeneous Nuclear 
Ribonucleoprotein M, Biomarkers

\section{Introduction}

Nonalcoholic fatty liver disease (NAFLD) ranges from simple steatosis to nonalcoholic steatohepatitis (NASH), and is the most common liver disease worldwide [1] [2] [3] [4] [5]. Although simple steatosis is considered a benign and nonprogressive condition, NASH is a potentially progressive disease that can lead to fibrosis, cirrhosis, and hepatocellular carcinoma [6] [7]. Currently, only invasive liver biopsy can distinguish between these diseases, but may cause severe complications in patients. Therefore, the development of noninvasive biomarkers is needed [8].

Advanced glycation endproducts (AGEs) are formed by the Maillard reaction, a nonenzymatic reaction between the ketone or aldehyde groups of sugars and the amino groups of proteins [9] [10]. Recent studies have suggested that AGEs can additionally arise from carbonyl compounds derived from the autoxidation of sugars and other metabolic pathways [11] [12]. It is well known that glycation of proteins alters their function [13] [14]. Our recent study suggested that glyceraldehyde-derived AGEs (Glycer-AGEs) accumulate in the liver of NASH patients, but not in that of patients with simple steatosis [15]. Furthermore, we detected the formation of Glycer-AGEs in human hepatocyte Hep3B cells exposed to high fructose concentrations, and identified the heterogeneous nuclear ribonucleoprotein M (HNRNPM) as a target for glycation in these cells. HNRNPM plays an important role in the regulation of gene expression by processing heterogeneous nuclear RNAs into mature mRNAs [16]. However, the effects of glycated HNRNPM on the pathophysiology of NASH remain poorly understood.

In this study, we examined gene expression changes caused by HNRNPM knockdown, and investigated genes that may be further developed as noninvasive biomarkers for Glycer-AGEs-related NASH.

\section{Materials and Methods}

\subsection{Chemicals}

All chemicals were commercial samples of high purity, and were used according to the manufacturer's instructions. Fructose was purchased from Wako Pure Chemical Industries, Ltd. (Osaka, Japan).

\subsection{Cell Cultures}

Hep3B and HepG2 cells were grown in Dulbecco's modified Eagle's medium (DMEM; Sigma-Aldrich, St. Louis, MO, USA) supplemented with $10 \%$ fetal bovine serum (Equitech-Bio, Kerrville, TX, USA), under standard cell culture conditions (humidified atmosphere, $5 \% \mathrm{CO}_{2}, 37^{\circ} \mathrm{C}$ ). Cells (Hep3B: $2 \times 10^{5}$ cells $/ \mathrm{mL}$, HepG2: $5 \times 10^{5}$ cells $/ \mathrm{mL}$ ) were seeded in culture dishes (BD Biosciences, Franklin Lakes, NJ, USA), and incubated for one day prior to use in experiments. Cells 
were incubated with or without fructose for one day or five days, to form glycated HNRNPM.

\subsection{Two-Dimensional Gradient Sodium Dodecyl Sulfate-Polyacrylamide Gel Electrophoresis (SDS-PAGE) and Gradient SDS-PAGE}

Cell lysates were prepared as described previously in [16], and protein concentrations were measured. In two-dimensional gradient SDS-PAGE, $100 \mu \mathrm{g}$ cell lysates were resolved on an agar gel ( $\mathrm{pH}$ range: 5 - 10) (ATTO, Tokyo, Japan), and a 5\% - 20\% SDS-polyacrylamide gradient gel (ATTO, Tokyo, Japan). In gradient SDS-PAGE, the cell lysates were resolved on a $4 \%-12 \%$ SDS-polyacrylamide gradient gel (Life Technologies, Carlsbad, CA, USA). All processes were performed according to the manufacturer's instructions.

\subsection{Western Blot Analysis}

Western blot analysis was performed as described previously in [16], using the antibodies: rabbit anti-Glycer-AGEs, mouse anti-HNRNPM (Millipore Corporation, Billerica, MA, USA), mouse anti- $\beta$-actin (Santa Cruz Biotechnology, Inc., Billerica, CA, USA), anti-rabbit IgG (GeneTex, Irvine, CA, USA), and anti-mouse IgG antibody (Dako, Agilent Technologies, Santa Clara, CA, USA).

\subsection{HNRNPM Knockdown}

Two Silencer Select siRNAs targeting HNRNPM (si1 and si2) (Thermo Fisher Scientific, Inc., Waltham, MA, USA) were used to downregulate the expression of HNRNPM in Hep3B cells. A nontargeting siRNA was used as control. siRNA transfection was performed using MISSION siRNA Transfection Reagent (Sigma-Aldrich) according to the manufacturer's instructions.

\subsection{Microarray Analysis}

Total RNA was isolated using ISOGEN II (Nippon Gene, Tokyo, Japan), and labeled with CyDye, using the Low Input Quick Amp Labeling kit per manufacturer's instructions (Agilent Technologies, Santa Clara, CA, USA). Briefly, cDNA was synthesized from the isolated RNA using the T7 promoter primer. Then, cRNA was synthesized using T7 RNA polymerase in the presence of either Cy3-CTP or Cy5-CTP. The labeled cRNAs were hybridized to the DNA microarray (SurePrint G3 Human Gene Expression $8 \times 60 \mathrm{~K}$ version 2.0, Agilent Technologies, Santa Clara, CA, USA), and washed using the recommended washing buffer. Detection was performed using the Agilent Microarray Scanner (Agilent Technologies, Santa Clara, CA, USA), and the data were analyzed using the Agilent Feature Extraction software 10.7.3.1 (Agilent Technologies, Santa Clara, CA, USA). The differences were considered significant at $p \leq 0.05$ (two-sided). The dataset was summarized and normalized using the Gene Spring software (Agilent Technologies, Santa Clara, CA, USA). Gene Ontology (GO) functional classification was performed using AmiGO2 [17]. 


\section{Results}

\subsection{Formation of Glycated HNRNPM Following Short- and Long-Term Exposure to Fructose}

The effects of short-(one day) or long-term (five days) exposure to fructose were examined by western blot analysis, using the anti-Glycer-AGEs antibody, following two-dimensional gel electrophoresis. In Hep3B cells, glycated HNRNPM was detected upon long-term exposure to fructose, but not upon short-term (one day) exposure. In addition, it was not detected in either of the controls (Figure 1(a)). No significant differences were found in the HNRNPM expression levels between the four conditions (Figure 1(a)). This suggests that HNRNPM is not glycated by short-term exposure to fructose. Furthermore, glycated HNRNPM was also detected in HepG2 cells upon long-term fructose exposure (Figure $1(\mathrm{~b}))$.

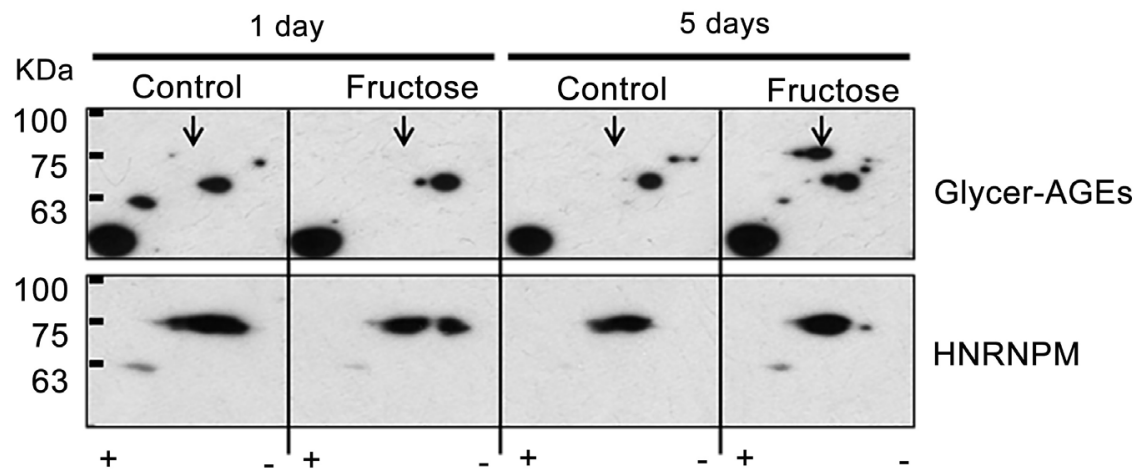

(a)

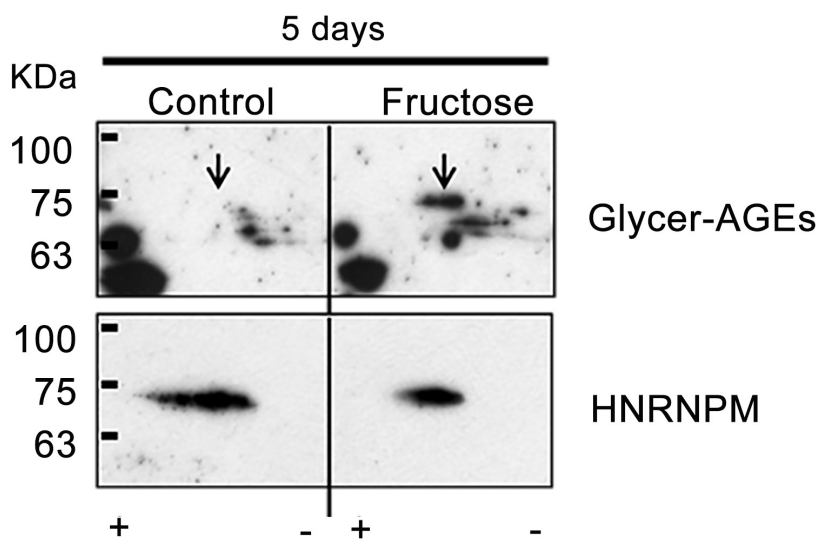

(b)

Figure 1. Western blot analysis of the glycated heterogeneous nuclear ribonucleoprotein M (HNRNPM). Cells were incubated with or without $10 \mathrm{mmol} / \mathrm{L}$ fructose for one day or five days. Cell lysates $(100 \mu \mathrm{g}$ protein/gel) were resolved using twodimensional gradient sodium dodecyl sulfate-polyacrylamide gel electrophoresis (SDS-PAGE). The blots were first probed with anti-glyceraldehyde-derived advanced glycation endproducts (Glycer-AGEs) antibody, and subsequently reprobed with anti-HNRNPM antibody. (a) Hep3B cells, (b) HepG2 cells. The arrows show the spots where glycated HNRNPM was identified. 


\subsection{HNRNPM Knockdown and Microarray Analysis}

It has been suggested that HNRNPM glycation leads to a decrease in its function. Thus, we performed microarray analysis to investigate gene expression changes in response to HNRNPM knockdown. Western blot analysis showed that HNRNPM expression was remarkably depleted in cells transfected with siRNAs targeting HNRNPM, compared with that in the control (Figure 2). A similar result was provided with other cell line (data not shown).

We compared the RNA expression levels in the HNRNPM knockdown and control samples. We identified 138 and 100 transcripts with expression levels 1.5 -fold higher and lower, respectively, compared with those in the control (Table 1, Table 2). Of these, 60 upregulated and 67 downregulated genes had GO terms.

\subsection{Identification of Up- and Down-regulated Genes Associated with the Extracellular Space}

We performed functional classification of the genes whose expression levels were influenced by HNRNPM knockdown. We extracted the GO terms that were associated with more than five genes in each of the up- or down-regulated gene set, and unified similar GO terms (Figure 3). We further analyzed the genes belonging to the category "cellular component," one of the three gene categories in GO. The ratio of genes classified as belonging to the cytoplasm, nucleus, membrane, endoplasmic reticulum, and extracellular space were no great difference in the upregulated genes and downregulated genes. We identified 14 upregulated and 9 downregulated genes annotated to the GO term "extracellular space," which may be further investigated as potential noninvasive biomarkers (Table 3, Table 4). Furthermore, among these genes, six each of the up- and down-regulated genes were annotated to the term "extracellular exosome" (Table 3, Table 4).

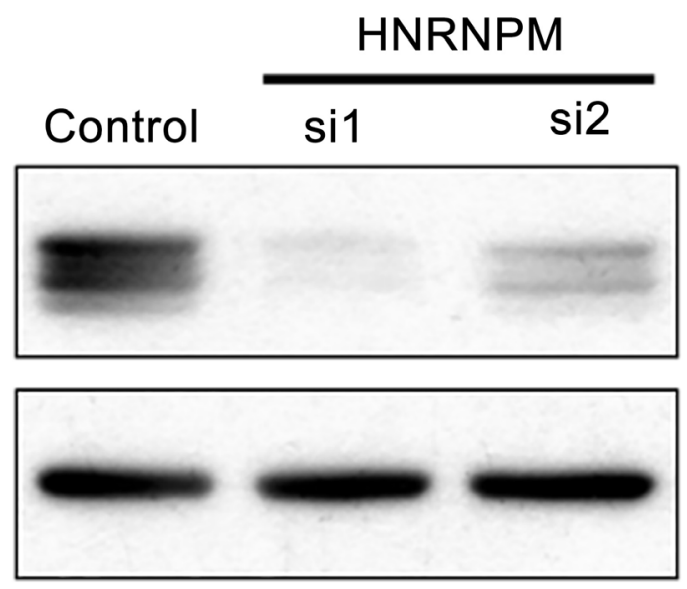

\section{HNRNPM}

\section{$\beta$-actin}

Figure 2. siRNA-mediated knockdown of heterogeneous nuclear ribonucleoprotein M (HNRNPM). Cell lysates were separated by SDS-PAGE and probed with anti-HNRNPM antibody. Equal protein loading was determined using anti- $\beta$-actin antibody. 
Table 1. The transcripts upregulated ( $\geq 1.5$-fold) by HNRNPM knockdown.

\begin{tabular}{|c|c|c|c|c|c|c|c|c|}
\hline Rank & Gene symbol & $\mathrm{FC}^{\dagger}$ & Rank & Gene symbol & $\mathrm{FC}^{\dagger}$ & Rank & Gene symbol & $\mathrm{FC}^{\dagger}$ \\
\hline 1 & $\operatorname{lnc}-P A R N-7$ & 10.1 & 47 & LINC01389 & 2.4 & 93 & $A \_33 \_P 3262022$ & 1.8 \\
\hline 2 & $\operatorname{lnc}-N A A L A D L 2-1$ & 8.5 & 48 & $G N A S-A S 1$ & 2.4 & 94 & $L U Z P 1$ & 1.8 \\
\hline 3 & ENST00000449119 & 7.8 & 49 & Inc-CLIC3-1 & 2.4 & 95 & $A T P 5 E$ & 1.8 \\
\hline 4 & $\operatorname{lnc}-C O L 18 A 1-2$ & 5.8 & 50 & $A \_21 \_P 0014212$ & 2.3 & 96 & ZNF548 & 1.8 \\
\hline 5 & A_33_P3346643 & 5.7 & 51 & WHSC1 & 2.3 & 97 & $L E A P 2$ & 1.8 \\
\hline 6 & Inc-RP11-539E17.5.1-1 & 5.0 & 52 & ENST00000390298 & 2.3 & 98 & $A K 130724$ & 1.8 \\
\hline 7 & $\ln c-D C T D-8$ & 5.0 & 53 & LOC100996579 & 2.3 & 99 & LOC100128242 & 1.8 \\
\hline 8 & $M M P 1$ & 4.2 & 54 & $\operatorname{lnc-NDUFS8-1}$ & 2.2 & 100 & LOC100289120 & 1.7 \\
\hline 9 & $\operatorname{lnc}-F O X F 1-1$ & 4.0 & 55 & $A \_33 \_P 3392350$ & 2.2 & 101 & PRR4 & 1.7 \\
\hline 10 & ENST00000590022 & 3.9 & 56 & $C A D M 2$ & 2.2 & 102 & $F B X O 36$ & 1.7 \\
\hline 11 & CFAP57 & 3.8 & 57 & ENST00000558690 & 2.2 & 103 & $H D A C 9$ & 1.7 \\
\hline 12 & XLOC_12_010772 & 3.8 & 58 & $C D C 6$ & 2.1 & 104 & $M R O H 1$ & 1.7 \\
\hline 13 & $A S P H D 2$ & 3.7 & 59 & $P R H 2$ & 2.1 & 105 & $\operatorname{lnc}-P R D M 13-4$ & 1.7 \\
\hline 14 & $C A 6$ & 3.7 & 60 & $F X Y D 1$ & 2.1 & 106 & $\ln c-A T X N 3 L-2$ & 1.7 \\
\hline 15 & $\operatorname{lnc}-C H T F 8-2$ & 3.6 & 61 & ENST00000534505 & 2.1 & 107 & PTGES2-AS1 & 1.7 \\
\hline 16 & KCNE5 & 3.5 & 62 & $P L A 2 G 4 F$ & 2.1 & 108 & C3orf52 & 1.7 \\
\hline 17 & $S P O N 1$ & 3.5 & 63 & $G S 1-259 H 13.2$ & 2.0 & 109 & LINCO0540 & 1.7 \\
\hline 18 & LOC441239 & 3.4 & 64 & $\operatorname{lnc}-A L D H 1 A 1-2$ & 2.0 & 110 & $F L C N$ & 1.7 \\
\hline 19 & ENST00000521016 & 3.3 & 65 & $Z F P 14$ & 2.0 & 111 & Inc-C6 orf $221-1$ & 1.7 \\
\hline 20 & $\operatorname{lnc}-M A E L-1$ & 3.3 & 66 & LOC100130502 & 2.0 & 112 & BC009492 & 1.7 \\
\hline 21 & NAP1LA & 3.3 & 67 & CAPS2 & 2.0 & 113 & $A T X N>L 1$ & 1.7 \\
\hline 22 & $H S D 17 B 3$ & 3.3 & 68 & SARS & 2.0 & 114 & LOC102724910 & 1.7 \\
\hline 23 & LINC01491 & 3.2 & 69 & $G N G T 1$ & 2.0 & 115 & ENST00000519159 & 1.7 \\
\hline 24 & $C H N 1$ & 3.2 & 70 & LOC388780 & 2.0 & 116 & LINC01578 & 1.7 \\
\hline 25 & $I G F 2 B P 1$ & 3.2 & 71 & $S L C 38 A 4$ & 2.0 & 117 & ENST00000513405 & 1.7 \\
\hline 26 & $G R E B 1$ & 3.1 & 72 & LOC101927571 & 1.9 & 118 & $\operatorname{lnc}-P M M 2-6$ & 1.7 \\
\hline 27 & $\operatorname{lnc}-K B T B D 6-1$ & 3.1 & 73 & $D S E$ & 1.9 & 119 & ZNF396 & 1.6 \\
\hline 28 & $O X N A D 1$ & 3.0 & 74 & ENST00000332359 & 1.9 & 120 & RECQL5 & 1.6 \\
\hline 29 & LOC102723456 & 2.9 & 75 & ENST00000538869 & 1.9 & 121 & $F A R P 1$ & 1.6 \\
\hline 30 & Inc-COPS4-1 & 2.8 & 76 & $\operatorname{lnc}-R A B 40 A L-1$ & 1.9 & 122 & $Z N F 460$ & 1.6 \\
\hline 31 & $\operatorname{lnc}-G A B P A-4$ & 2.8 & 77 & $C T B P 2$ & 1.9 & 123 & SMIM7 & 1.6 \\
\hline 32 & Inc-MAGEA8-2 & 2.7 & 78 & ENST00000566803 & 1.9 & 124 & TMEM201 & 1.6 \\
\hline 33 & $A O A H-I T 1$ & 2.7 & 79 & A_33_P3298251 & 1.9 & 125 & GOSR2 & 1.6 \\
\hline 34 & $G I P R$ & 2.7 & 80 & LOC646938 & 1.8 & 126 & FSTL5 & 1.6 \\
\hline 35 & $R N F 213$ & 2.7 & 81 & $I T G B L 1$ & 1.8 & 127 & $G S A P$ & 1.6 \\
\hline 36 & $C T R L$ & 2.7 & 82 & POLA1 & 1.8 & 128 & $D N A J B 6$ & 1.6 \\
\hline 37 & PER2 & 2.7 & 83 & $S P I 1$ & 1.8 & 129 & $R P L 28$ & 1.6 \\
\hline 38 & XLOC_12_003888 & 2.6 & 84 & $S U V 420 H 1$ & 1.8 & 130 & ENST00000562341 & 1.6 \\
\hline 39 & $\operatorname{lnc}-S L C 15 A 4-5$ & 2.6 & 85 & LOC646652 & 1.8 & 131 & $A \_33 \_P 3239102$ & 1.6 \\
\hline 40 & $L R R C 9$ & 2.6 & 86 & LINC00476 & 1.8 & 132 & EDIL3 & 1.6 \\
\hline 41 & $Y T H D C 1$ & 2.5 & 87 & $G P C P D 1$ & 1.8 & 133 & $M Y L K-A S 1$ & 1.6 \\
\hline 42 & $D P Y 19 L 2 P 3$ & 2.5 & 88 & LOC101929542 & 1.8 & 134 & $A F 119870$ & 1.6 \\
\hline 43 & NEAT1 & 2.5 & 89 & THC2626681 & 1.8 & 135 & LOC101927815 & 1.5 \\
\hline 44 & CFAP36 & 2.5 & 90 & $B D N F-A S$ & 1.8 & 136 & $D D X 31$ & 1.5 \\
\hline 45 & $R B M B 3$ & 2.4 & 91 & $L E M D 1$ & 1.8 & 137 & $T H O C 7-A S 1$ & 1.5 \\
\hline 46 & $P S M F 1$ & 2.4 & 92 & $A \_33 \_P 3238325$ & 1.8 & 138 & ENST00000412362 & 1.5 \\
\hline
\end{tabular}

FC: Fold change. ${ }^{\dagger}$ Fold change indicates 1.5 average or more in 2 analysis (control vs sil or si2), and shaded cells indicate $\geq 3$. 0 -fold. 
Table 2. The transcripts downregulated ( $\geq 1.5$-fold) by HNRNPM knockdown.

\begin{tabular}{|c|c|c|c|c|c|c|c|c|}
\hline Rank & Gene symbol & $\mathrm{FC}^{\dagger}$ & Rank & Gene symbol & $\mathrm{FC}^{\dagger}$ & Rank & Gene symbol & $\mathrm{FC}^{\dagger}$ \\
\hline 1 & NIPAL4 & 3.9 & 35 & TFPI & 2.0 & 69 & A_33_P3262022 & 1.7 \\
\hline 2 & MIPEPP3 & 3.8 & 36 & $S T K 38 L$ & 2.0 & 70 & $L U Z P 1$ & 1.7 \\
\hline 3 & ENST00000569087 & 3.7 & 37 & $\operatorname{lnc}-\mathrm{C} 3$ orf $52-1$ & 2.0 & 71 & $A T P 5 E$ & 1.7 \\
\hline 4 & FLJ45513 & 3.6 & 38 & $A U H$ & 2.0 & 72 & ZNF548 & 1.7 \\
\hline 5 & $N U D C D 3$ & 3.4 & 39 & $C D 59$ & 2.0 & 73 & $L E A P 2$ & 1.7 \\
\hline 6 & $X L O C \_12 \_012319$ & 3.4 & 40 & $E P B 41 L 5$ & 2.0 & 74 & $A K 130724$ & 1.7 \\
\hline 7 & $C C P G 1$ & 3.2 & 41 & $R N F 112$ & 2.0 & 75 & LOC100128242 & 1.7 \\
\hline 8 & $T Y W 3$ & 3.2 & 42 & $Z D H H C 11$ & 1.9 & 76 & LOC100289120 & 1.7 \\
\hline 9 & $M B P$ & 3.1 & 43 & $F A R P 2$ & 1.9 & 77 & PRR 4 & 1.6 \\
\hline 10 & $O B F C 1$ & 2.9 & 44 & $\operatorname{lnc}-S K I V 2 L 2-1$ & 1.9 & 78 & FBXO36 & 1.6 \\
\hline 11 & PHF7 & 2.8 & 45 & $P P P 2 R 1 B$ & 1.9 & 79 & $H D A C 9$ & 1.6 \\
\hline 12 & LINCO0400 & 2.7 & 46 & ERICH1 & 1.9 & 80 & $M R O H 1$ & 1.6 \\
\hline 13 & $H M G B 3$ & 2.5 & 47 & $\mathrm{CDH} 26$ & 1.9 & 81 & Inc-PRDM13-4 & 1.6 \\
\hline 14 & QRICH2 & 2.5 & 48 & $H S F 2$ & 1.9 & 82 & $\ln c-A T X N 3 L-2$ & 1.6 \\
\hline 15 & $R B M 4$ & 2.4 & 49 & $N D E 1$ & 1.9 & 83 & $P T G E S 2-A S 1$ & 1.6 \\
\hline 16 & SEPT8 & 2.4 & 50 & $S C L Y$ & 1.9 & 84 & C3orf52 & 1.6 \\
\hline 17 & ENST00000527983 & 2.3 & 51 & MTL5 & 1.9 & 85 & LINCO0540 & 1.6 \\
\hline 18 & RECQLA & 2.3 & 52 & TM9SF4 & 1.9 & 86 & $F L C N$ & 1.6 \\
\hline 19 & $Z N F 641$ & 2.3 & 53 & $Z N F 862$ & 1.9 & 87 & $\operatorname{lnc}-$ C6 orf $221-1$ & 1.6 \\
\hline 20 & ENST00000550019 & 2.3 & 54 & C6orf 118 & 1.8 & 88 & BC009492 & 1.6 \\
\hline 21 & LOC101927641 & 2.2 & 55 & $I L 17 R A$ & 1.8 & 89 & $A T X N 7 L 1$ & 1.6 \\
\hline 22 & C16orf 90 & 2.2 & 56 & TMEM240 & 1.8 & 90 & LOC102724910 & 1.6 \\
\hline 23 & $\operatorname{lnc}-E I F 2 A K 4-4$ & 2.2 & 57 & $D C B L D 1$ & 1.8 & 91 & ENST00000519159 & 1.6 \\
\hline 24 & $W D R 4$ & 2.2 & 58 & $T X N R D 3$ & 1.8 & 92 & LINC01578 & 1.6 \\
\hline 25 & CRTAP & 2.2 & 59 & TMCO3 & 1.8 & 93 & ENST00000513405 & 1.6 \\
\hline 26 & CNST & 2.2 & 60 & $U B X N 7$ & 1.8 & 94 & $\ln c-P M M 2-6$ & 1.6 \\
\hline 27 & $A K R 1 E 2$ & 2.2 & 61 & $\operatorname{lnc}-Y I F 1 A-6$ & 1.8 & 95 & ZNF396 & 1.6 \\
\hline 28 & $A K 090765$ & 2.1 & 62 & TEX19 & 1.8 & 96 & RECQL5 & 1.6 \\
\hline 29 & $\operatorname{lnc}-T X L N B-3$ & 2.1 & 63 & TMTC3 & 1.7 & 97 & $F A R P 1$ & 1.6 \\
\hline 30 & $W N K 1$ & 2.1 & 64 & $B L C A P$ & 1.7 & 98 & $Z N F 460$ & 1.5 \\
\hline 31 & $D C U N 1 D 4$ & 2.1 & 65 & $E I F 4 G 3$ & 1.7 & 99 & $S M I M 7$ & 1.5 \\
\hline 32 & ENST00000606907 & 2.1 & 66 & $A D A T 2$ & 1.7 & 100 & TMEM201 & 1.5 \\
\hline 33 & $\operatorname{lnc}-A C T R 6-1$ & 2.1 & 67 & $D B N D D 2$ & 1.7 & & & \\
\hline 34 & $Z H X 3$ & 2.1 & 68 & $D N A J B 6$ & 1.7 & & & \\
\hline
\end{tabular}

FC: Fold change. ${ }^{\dagger}$ Fold change indicates 1.5 average or more in 2 analysis (control vs si1 or si2), and shaded cells indicate $\geq 3$. 0 -fold.

\section{Discussion}

NASH is recognized as a component of the metabolic syndrome and is closely associated with insulin resistance and disorders of glucose and lipid metabolism [18] [19] [20] [21]. We recently demonstrated that in NASH patients, Glycer-AGEs are elevated in the sera and simultaneously accumulated in the liver

[15]. The accumulation of Glycer-AGEs in the liver is caused by the glycation of 


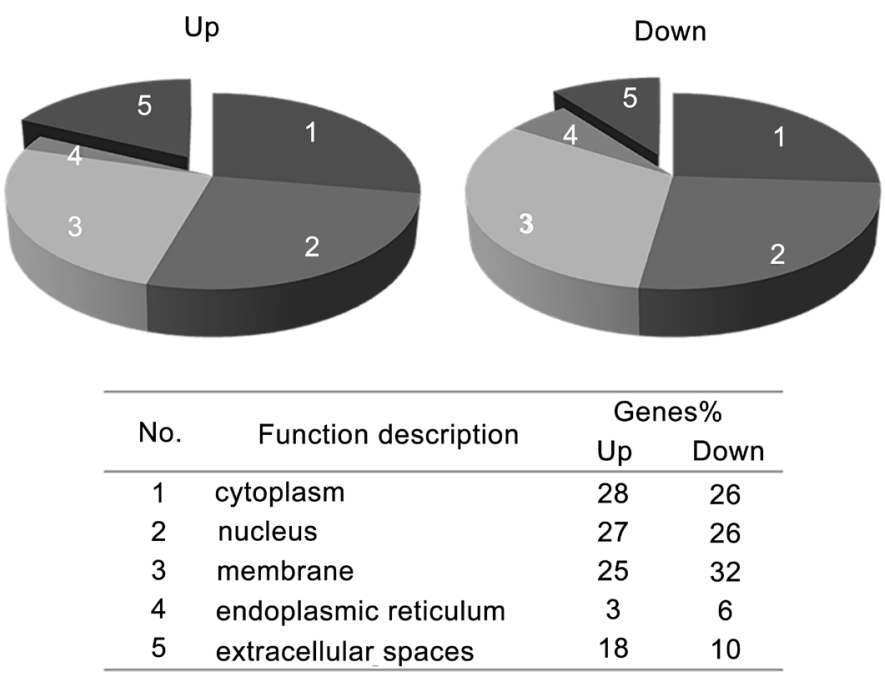

Figure 3. Gene Ontology (GO) classification of genes up- or down-regulated by HNRNPM knockdown. The gene functional annotations were classified on the basis of the GO term "cellular component."

Table 3. List of the up-regulated genes associated with the extracellular space.

\begin{tabular}{cc}
\hline Gene symbol & Gene title \\
\hline$M M P 1$ & matrix metallopeptidase 1 (interstitial collagenase) \\
$C A 6^{\dagger \dagger}$ & carbonic anhydrase VI \\
$S P O N 1$ & spondin 1, extracellular matrix protein \\
$G R E B 1^{\dagger \dagger}$ & Growth Regulation By Estrogen In Breast Cancer 1 \\
$C T R L$ & chymotrypsin-like \\
$P R H 2$ & proline-rich protein HaeIII subfamily2 \\
$S A R S^{\dagger \dagger}$ & seryl-tRNA synthetase \\
$I T G B L 1$ & integrin, beta-like 1 (with EGF-like repeat domains) \\
$L U Z P 1^{\dagger \dagger}$ & leucine zipper protein 1 \\
$L E A P 2$ & liver expressed antimicrobial peptide 2 \\
PRR 4 & proline rich 4 (lacrimal) \\
$F S T L 5$ & follistatin-like 5 \\
$R P L 28^{\dagger \dagger}$ & ribosomal protein L28 \\
EDIL3 ${ }^{\dagger \dagger}$ & EGF-like repeats and discoidin I-like domains 3
\end{tabular}

${ }^{\dagger \dagger}$ indicates gene associated with the extracellular exosome.

intracellular proteins [22]. Previously, we showed that in Hep3B cells, intracellular Glycer-AGEs increased in response to fructose, and HNRNPM was one of the target proteins for glycation [16]. In this study, we showed that HNRNPM was glycated after long-term exposure to fructose, but not after short-term exposure (Figure 1(a)). The generation of glycated HNRNPM after long-term exposure to fructose was also confirmed in HepG2 cells (Figure 1(b)). This is consistent with studies showing that Glycer-AGEs are formed by a nonenzymatic reaction dependent on the accumulation of intracellular glyceraldehyde, which is produced by fructose metabolism. Moreover, HNRNPM is suggested to be more easily glycated than other hepatocyte proteins [16]. 
Table 4. List of the down-regulated genes associated with the extracellular space.

\begin{tabular}{|c|c|}
\hline Gene symbol & Gene title \\
\hline CRTAP & cartilage associated protein \\
\hline$A K R 1 E 2^{\dagger \dagger}$ & aldo-keto reductase family 1, member $E 2$ \\
\hline TFPI & tissue factor pathway inhibitor (lipoprotein-associated coagulation inhibitor) \\
\hline$C D 59^{\dagger \dagger}$ & CD59 molecule, complement regulatory protein \\
\hline$P P P 2 R 1 B^{\dagger \dagger}$ & protein phosphatase 2 , regulatory subunit $A$, beta \\
\hline$I L 17 R A$ & interleukin 17 receptor $A$ \\
\hline$A T P 6 V 1 C 1^{\dagger \dagger}$ & ATPase, $H+$ transporting, lysosomal $42 \mathrm{kDa}$, V1 subunit $C 1$ \\
\hline$G N A B^{\dagger \dagger}$ & $\begin{array}{l}\text { guanine nucleotide binding protein ( } G \text { protein), alpha inhibiting activity } \\
\text { polypeptide } 3\end{array}$ \\
\hline$N 4 B P 2 L 2^{\dagger \dagger}$ & NEDD4 binding protein 2 -like 2 \\
\hline
\end{tabular}

${ }^{\dagger+}$ indicates gene associated with the extracellular exosome.

During glycation, the lysine and arginine side chains in the protein are modified by reducing sugars, and this causes functional changes in the protein [23] [24]. HNRNPM has an unusual hexapeptide-repeat region, rich in methionine and arginine residues (MR repeat motif), which may participate in the formation of AGEs [25]. HNRNPM plays an important role in the processing of mature mRNAs from heterogeneous nuclear RNAs to regulate gene expression. HNRNPM directly binds to nascent RNA polymerase II transcripts [25]. In RNAbinding proteins, the basic residues lysine and arginine are important for the RNA-protein interactions [26] [27] [28] [29] [30], suggesting that the function of HNRNPM is suppressed by glycation.

Microarray analysis showed that multiple genes were up- or down-regulated after HNRNPM knockdown compared with those in the control (Table 1, Table 2). Among the genes regulated by HNRNPM knockdown, $M M P 1$ is associated with the pathophysiology of NASH. Sookoian et al. reported that the expression of $M M P 1$ is significantly higher in NASH compared with that in simple steatosis, and this may contribute to an increased risk of atherosclerosis [31]. We suggest that this effect of NASH on MMP1 expression might be mediated via the loss of HNRNPM function.

We demonstrated that the expression of 23 genes associated with the extracellular space (including the extracellular exosome) was altered upon HNRNPM knockdown (Table 3, Table 4). Because the protein products of these genes are released or secreted into the blood, they may be easily detected by noninvasive methods. We thus plan to analyze the changes in expression levels of these proteins to develop a noninvasive method to measure the formation and accumulation of intracellular Glycer-AGEs. Among these genes, $M M P 1$ is known to be closely associated with NASH, but the roles of the other genes are not well known. Therefore, further investigations, including protein expression analysis in the sera of NASH patients, will be necessary to elucidate their roles.

To summarize, we have demonstrated that HNRNPM knockdown causes gene expression changes, and our work identifies the possibility that the loss of HN- 
RNPM function can be noninvasively measured. Our results suggest that the identified extracellular region-associated genes have the potential to serve as noninvasive biomarkers for Glycer-AGEs-related NASH.

\section{Acknowledgements}

This work was supported in part by JSPS KAKENHI Grant Numbers JP16K00931 (for Nagamine) and JP25282029 \& JP16H01811 (for Takeuchi), by MEXT: Regional Innovation Strategy Support Program (for Takeuchi), by the Hokkoku Foundation for Cancer Research (for Takeuchi).

\section{References}

[1] Tappy, L. and Lê, K.A. (2010) Metabolic Effects of Fructose and the Worldwide Increase in Obesity. Physiological Reviews, 90, 23-46. https://doi.org/10.1152/physrev.00019.2009

[2] Dekker, M.J., Su, Q., Baker, C., Rutledge, A.C. and Adeli, K. (2010) Fructose: A Highly Lipogenic Nutrient Implicated in Insulin Resistance, Hepatic Steatosis, and the Metabolic Syndrome. American Journal of Physiology. Endocrinology and Metabolism, 299, E685-E694. https://doi.org/10.1152/ajpendo.00283.2010

[3] Vos, M.B. and Lavine, J.E. (2013) Dietary Fructose in Nonalcoholic Fatty Liver Disease. Hepatology, 57, 2525-2531. https://doi.org/10.1002/hep.26299

[4] Attar, B.M. and Van Thiel, D.H. (2013) Current Concepts and Management Approaches in Nonalcoholic Fatty Liver Disease. The Scientific World Journal, 2013, Article ID: 481893. https://doi.org/10.1155/2013/481893

[5] Conlon, B.A., Beasley, J.M., Aebersold, K., Jhangiani, S.S. and Wylie-Rosett, J. (2013) Nutritional Management of Insulin Resistance in Nonalcoholic Fatty Liver Disease (NAFLD). Nutrients, 5, 4093-4114. https://doi.org/10.3390/nu5104093

[6] Matteoni, C.A., Younossi, Z.M., Gramlich, T., Boparai, N., Liu, Y.C. and McCullough, A.J. (1999) Nonalcoholic Fatty Liver Disease: A Spectrum of Clinical and Pathological Severity. Gastroenterology, 116, 1413-1419. https://doi.org/10.1016/S0016-5085(99)70506-8

[7] Dam-Larsen, S., Franzmann, M., Andersen, I.B., et al. (2004) Long Term Prognosis of Fatty Liver: Risk of Chronic Liver Disease and Death. Gut, 53, 750-755. https://doi.org/10.1136/gut.2003.019984

[8] Guha, I.N., Parkes, J., Roderick, P., et al. (2008) Noninvasive Markers of Fibrosis in Nonalcoholic Fatty Liver Disease: Validating the European Liver Fibrosis Panel and Exploring Simple Markers. Hepatology, 47, 455-460. https://doi.org/10.1002/hep.21984

[9] Al-Abed, Y., Kapurniotu, A. and Bucala, R. (1999) Advanced Glycation end Products: Detection and Reversal. Methods in Enzymology, 309, 152-172.

[10] Vlassara, H. and Palace, M.R. (2002) Diabetes and Advanced Glycation Endproducts. Journal of Internal Medicine, 251, 87-101. https://doi.org/10.1046/j.1365-2796.2002.00932.x

[11] Glomb, M.A. and Monnier, V.M. (1995) Mechanism of Protein Modification by Glyoxal and Glycolaldehyde, Reactive Intermediates of the Maillard Reaction. Journal of Biological Chemistry, 270, 10017-10026. https://doi.org/10.1074/jbc.270.17.10017

[12] Thornalley, P.J., Langborg, A. and Minhas, H.S. (1999) Formation of Glyoxal, Methylglyoxal and 3-Deoxyglucosone in the Glycation of Proteins by Glucose. Bio- 
chemical Journal, 344, 109-116. https://doi.org/10.1042/bj3440109

[13] Hamelin, M., Mary, J., Vostry, M., Friguet, B. and Bakala, H. (2007) Glycation Damage Targets Glutamate Dehydrogenase in the Rat Liver Mitochondrial Matrix during Aging. The FEBS Journal, 274, 5949-5961. https://doi.org/10.1111/j.1742-4658.2007.06118.x

[14] Kumar, P.A., Kumar, M.S. and Reddy, G.B. (2007) Effect of Glycation on AlphaCrystallin Structure and Chaperone-Like Function. Biochemical Journal, 408, 251258. https://doi.org/10.1042/BJ20070989

[15] Hyogo, H., Yamagishi, S., Iwamoto, K., et al. (2007) Elevated Levels of Serum Advanced Glycation End Products in Patients with Non-Alcoholic Steatohepatitis. Journal of Gastroenterology and Hepatology, 22, 1112-1119. https://doi.org/10.1111/j.1440-1746.2007.04943.x

[16] Takino, J., Nagamine, K., Takeuchi, M. and Hori, T. (2015) In Vitro Identification of Nonalcoholic Fatty Liver Disease-Related Protein hnRNPM. World Journal of Gastroenterology, 21, 1784-1793. https://doi.org/10.3748/wjg.v21.i6.1784

[17] Carbon, S., Ireland, A., Mungall, C.J., et al. (2009) AmiGO: Online Access to Ontology and Annotation Data. Bioinformatics, 25, 288-289.

https://doi.org/10.1093/bioinformatics/btn615

[18] Ludwig, J., Viggiano, T.R., McGill, D.B. and Oh, B.J. (1980) Nonalcoholic Steatohepatitis: Mayo Clinic Experiences with a Hitherto Unnamed Disease. Mayo Clinic Proceedings, 55, 434-438.

[19] Marchesini, G., Brizi, M., Bianchi, G., et al. (2001) Nonalcoholic Fatty Liver Disease: A Feature of the Metabolic Syndrome. Diabetes, 50, 1844-1850. https://doi.org/10.2337/diabetes.50.8.1844

[20] Chitturi, S., Abeygunasekera, S., Farrell, G.C., et al. (2002) NASH and Insulin Resistance: Insulin Hypersecretion and Specific Association with the Insulin Resistance Syndrome. Hepatology, 35, 373-379. https://doi.org/10.1053/jhep.2002.30692

[21] Marchesini, G., Bugianesi, E., Forlani, G., et al. (2003) Nonalcoholic Fatty Liver, Steatohepatitis, and the Metabolic Syndrome. Hepatology, 37, 917-923. https://doi.org/10.1053/jhep.2003.50161

[22] Sato, T., Wu, X., Shimogaito, N., Takino, J., Yamagishi, S. and Takeuchi, M. (2009) Effects of High-AGE Beverage on RAGE and VEGF Expressions in the Liver and Kidneys. European Journal of Nutrition, 48, 6-11. https://doi.org/10.1007/s00394-008-0753-4

[23] Ahmed, M.U., Dunn, J.A., Walla, M.D., Thorpe, S.R. and Baynes, J.W. (1988) Oxidative Degradation of Glucose Adducts to Protein. Formation of 3-(N Epsilon-Lysino)-Lactic Acid from Model Compounds and Glycated Proteins. The Journal of Biological Chemistry, 263, 8816-8821.

[24] Iijima, K., Murata, M., Takahara, H., Irie, S. and Fujimoto, D. (2000) Identification of $\mathrm{N} \Omega$-carboxymethylarginine as a Novel Acid-Labile Advanced Glycation End Product in Collagen. Biochemical Journal, 347, 23-27.

https://doi.org/10.1042/bj3470023

[25] Datar, K.V., Dreyfuss, G. and Swanson, M.S. (1993) The Human HNRNPM Proteins: Identification of a Methionine/Arginine-Rich Repeat Motif in Ribonucleoproteins. Nucleic Acids Research, 21, 439-446. https://doi.org/10.1093/nar/21.3.439

[26] Jones, S., Daley, D.T., Luscombe, N.M., Berman, H.M. and Thornton, J.M. (2001) Protein-RNA Interactions: A Structural Analysis. Nucleic Acids Research, 29, 943954. https://doi.org/10.1093/nar/29.4.943

[27] Kim, H., Jeong, E., Lee, S.W. and Han, K. (2003) Computational Analysis of Hy- 
drogen Bonds in Protein-RNA Complexes for Interaction Patterns. FEBS Letters, 552, 231-239. https://doi.org/10.1016/S0014-5793(03)00930-X

[28] Lejeune, D., Delsaux, N., Charloteaux, B., Thomas, A. and Brasseur, R. (2005) Protein-Nucleic Acid Recognition: Statistical Analysis of Atomic Interactions and Influence of DNA Structure. Proteins: Structure, Function, and Bioinformatics, 61, 258-271. https://doi.org/10.1002/prot.20607

[29] Ellis, J.J., Broom, M. and Jones, S. (2007) Protein-RNA Interactions: Structural Analysis and Functional Classes. Proteins. Structure, Function, and Bioinformatics, 66, 903-911. https://doi.org/10.1002/prot.21211

[30] Ciriello, G., Gallina, C. and Guerra, C. (2010) Analysis of Interactions between Ribosomal Proteins and RNA Structural Motifs. BMC Bioinformatics, 11, S41. https://doi.org/10.1186/1471-2105-11-S1-S41

[31] Sookoian, S., Gianotti, T.F., Rosselli, M.S., Burgueno, A.L., Castaño, G.O. and Pirola, C.J. (2011) Liver Transcriptional Profile of Atherosclerosis-Related Genes in Human Nonalcoholic Fatty Liver Disease. Atherosclerosis, 218, 378-385.

https://doi.org/10.1016/j.atherosclerosis.2011.05.014

\section{Submit or recommend next manuscript to SCIRP and we will provide best service for you:}

Accepting pre-submission inquiries through Email, Facebook, LinkedIn, Twitter, etc. A wide selection of journals (inclusive of 9 subjects, more than 200 journals)

Providing 24-hour high-quality service

User-friendly online submission system

Fair and swift peer-review system

Efficient typesetting and proofreading procedure

Display of the result of downloads and visits, as well as the number of cited articles

Maximum dissemination of your research work

Submit your manuscript at: http://papersubmission.scirp.org/

Or contactajmb@scirp.org 